University of Nebraska - Lincoln

DigitalCommons@University of Nebraska - Lincoln

U.S. Department of Veterans Affairs Staff

Publications

U.S. Department of Veterans Affairs

2004

\title{
Characterization of a KCNQ1/KVLQT1 polymorphism in Asian families with LQT2: implications for genetic testing
}

\author{
Dipika Sharma \\ University of California \\ Kathryn A. Glatter \\ University of California \\ V. Timofeyev \\ University of California \\ Dipika Tuteja \\ University of California \\ Zhao Zhang \\ University of California \\ See next page for additional authors
}

Follow this and additional works at: https://digitalcommons.unl.edu/veterans

Sharma, Dipika; Glatter, Kathryn A.; Timofeyev, V.; Tuteja, Dipika; Zhang, Zhao; Rodriguez, Jennifer; Tester, David J.; Low, Reginald; Scheinman, Melvin M.; Ackerman, Michael J.; and Chiamvimonvat, Nipavan, "Characterization of a KCNQ1/KVLQT1 polymorphism in Asian families with LQT2: implications for genetic testing" (2004). U.S. Department of Veterans Affairs Staff Publications. 73.

https://digitalcommons.unl.edu/veterans/73

This Article is brought to you for free and open access by the U.S. Department of Veterans Affairs at DigitalCommons@University of Nebraska - Lincoln. It has been accepted for inclusion in U.S. Department of Veterans Affairs Staff Publications by an authorized administrator of DigitalCommons@University of Nebraska - Lincoln. 


\section{Authors}

Dipika Sharma, Kathryn A. Glatter, V. Timofeyev, Dipika Tuteja, Zhao Zhang, Jennifer Rodriguez, David J.

Tester, Reginald Low, Melvin M. Scheinman, Michael J. Ackerman, and Nipavan Chiamvimonvat 
Original Article

\title{
Characterization of a $K C N Q 1 / K V L Q T 1$ polymorphism in Asian families with LQT2: implications for genetic testing
}

\author{
Dipika Sharma $^{\text {a,1 }}$, Kathryn A. Glatter ${ }^{\text {a,1 }}$, V. Timofeyev ${ }^{\text {a }}$, Dipika Tuteja ${ }^{\text {a }}$, Zhao Zhang ${ }^{\text {a }}$ \\ Jennifer Rodriguez ${ }^{\mathrm{a}}$, David J. Tester ${ }^{\mathrm{b}}$, Reginald Low ${ }^{\mathrm{a}}$, Melvin M. Scheinman ${ }^{\mathrm{c}}$, \\ Michael J. Ackerman ${ }^{\mathrm{b}}$, Nipavan Chiamvimonvat ${ }^{\mathrm{a}, *, \mathrm{~d}}$ \\ ${ }^{a}$ Department of Internal Medicine, Division of Cardiovascular Medicine, University of California, \\ Davis One Shields Avenue, TB 172 Davis, CA 95616, USA \\ ${ }^{b}$ Departments of Medicine, Pediatrics, and Molecular Pharmacology, Divisions of Cardiovascular Diseases and Pediatric Cardiology, \\ Mayo Clinic, Rochester, MN 55905, USA \\ ${ }^{c}$ Department of Medicine, Cardiac Electrophysiology, University of California, San Francisco, CA 94143-1354, USA \\ ${ }^{d}$ Department of Veterans Affairs, Research Service, Northern California Health Care System, Mather, CA 95655, USA
}

Received 18 March 2004; received in revised form 19 March 2004; accepted 31 March 2004

Available online 20 May 2004

\begin{abstract}
Congenital long QT syndrome (LQTS) is a genetic disease that predisposes affected individuals to arrhythmias, syncope, and sudden death. Mutations in several ion channel genes have been discovered in different families with LQTS: KCNQ1 (KVLQT1, LQT1), KCNH2 (HERG, LQT2), SCN5A (LQT3), KCNE1 (minK, LQT5), and KCNE2 (MiRP1, LQT6). Previously, the P448R-KVLQT1 missense mutation has been reported as an LQT1-causing mutation. In this report, we demonstrate the presence of the P448R polymorphism in two, unrelated Chinese LQTS families. Although absent from 500 reference alleles derived from 150 white and 100 African-American subjects, P448R was present in $14 \%$ of healthy Chinese volunteers. Given the inconsistencies between the genotype (LQT1) and clinical phenotype (LQT2) in our two LQTS families, together with the finding that the P448R appears to be a common, ethnic-specific polymorphism, mutational analysis was extended to the other LQTS-causing genes resulting in the identification of distinct $H E R G$ missense mutations in each of these two families. Heterologous expression of P448R-KVLQT1 yielded normal, wild-type (WT) currents. In contrast, the two unique HERG mutations resulted in dominant-negative suppression of the WT HERG channel. Our study has profound implications for those engaged in genetic research. Importantly, one child of the original proband was initially diagnosed with LQT1 based upon the presence of P448R-KVLQT1 and was treated with beta-blockers. However, he did not possess the subsequently determined LQT2-causing mutation. On the other hand, his untreated P448R-negative brother harbored the true, disease-causing HERG mutation. These findings underscore the importance of distinguishing channel polymorphisms from mutations pathogenic for LQTS and emphasize the importance of using appropriate ethnically matched controls in the genotypic analysis of LQTS.

(C) 2004 Elsevier Ltd. All rights reserved.
\end{abstract}

Keywords: LQTS; Genetic disease; HERG mutation

\section{Introduction}

Congenital long QT syndrome (LQTS) is a heritable disorder associated with delayed cardiac repolarization, prolonged electrocardiographic QT intervals, development of ventricular arrhythmias, and sudden death. Mutations in at

\footnotetext{
* Corresponding author. Tel.: +1-530-752-4712; fax: +1-530-752-3264.

E-mail address: nchiamvimonvat@ucdavis.edu (N. Chiamvimonvat).

${ }^{1}$ These two authors have contributed equally to the work described in this manuscript.
}

least six cardiac ion channel genes have been discovered in different families with LQTS: KCNQ1 (KVLQT1, LQT1), KCNH2 (HERG, LQT2), SCN5A (LQT3), KCNE1 (minK, LQT5), KCNE2 (MiRP1, LQT6) and KCNE2 (Kir 2.1, LQT7)[1-10] (for review see Ref. [11]). More recently, a mutation in $A N K B$ encoding ankyrin-B (also known as ankyrin-2), a member of a family of membrane adapters, has been shown to underlie LQT4 [12].

KVLQT1 is located on chromosome $11 \mathrm{p} 5.5$. The gene encodes a voltage-gated $\mathrm{K}^{+}$channel $\alpha$ subunit. Mutations of KVLQT1 cause LQTS type 1 (LQT1), the most common 
form of LQTS. KCNE1, located on chromosome 21, encodes a 129-amino acid protein, which co-assembles with KVLQT1 to form a slowly activating delayed-rectifier $\mathrm{K}^{+}$channel $\left(I_{\mathrm{Ks}}\right)$ [13]. Mutations in HERG, located on chromosome 7q35q36, cause LQTS type 2 (LQT2) and represent $45 \%$ of the known LQTS defects. This gene encodes an $\alpha$ subunit that forms cardiac $I_{\mathrm{Kr}}$, a rapidly activating delayed-rectifier $\mathrm{K}^{+}$ channel [10]. KCNE2 is located on chromosome 21 and co-assembles with $H E R G \alpha$ subunits to form cardiac $I_{\mathrm{Kr}}$ channels [6]. Both $I_{\mathrm{Kr}}$ and $I_{\mathrm{Ks}}$ are responsible for termination of the plateau phase of the action potential (AP).

Mutations in SCN5A associated with LQTS destabilize the channel inactivation gate, leading to a resultant AP prolongation, i.e. gain-of-function mutations. $\mathrm{K}^{+}$channels, on the other hand, consist of four identical pore-forming subunits ( $\alpha$ subunits) that co-assemble to form a functional channel together with smaller $\beta$ subunits; this is in contrast to the $\mathrm{Na}^{+}$and $\mathrm{Ca}^{2+}$ channels, which are composed of one pore-forming subunit ( $\alpha$ subunit) that has a tetrameric-repeat structure associated with smaller $\beta$ subunits [14]. At least two molecular mechanisms account for reduced KVLQT1, $H E R G, K C N E 1$, and KCNE2 function in LQTS [11]. In the first, abnormal subunits are formed that do not assemble with normal subunits. These loss-of-function mutations result in a $\sim 50 \%$ reduction in the number of functional channels. In the second mechanism, abnormal subunits can assemble with normal subunits, forming heterotetramers with varying stoichiometry. However, channels formed from normal and mutant subunits have reduced or no function. The net effect is a greater than $50 \%$ reduction in channel function, or a dominant-negative effect on the wild-type (WT) subunits.

Previously, the P448R-KVLQT1 missense mutation has been reported as an LQT1-causing mutation [15]. In our current study, we demonstrated the presence of P448R in two Chinese LQTS families as well as in $14 \%$ of normal healthy volunteers of Chinese descent without clinical evidence or family history of LQTS. These findings suggest that P448RKVLQT1 represents an ethnic-specific, common polymorphism rather than an LQT1-causing mutation. Consequently, mutational analysis was extended to additional LQTScausing genes resulting in the identification of distinct HERG missense mutations in each of the two patients. To directly document the significance of the two newly identified HERG variants as the LQT2 disease-causing mutations, we performed functional analysis of the two novel HERG mutations identified in the two patients as well as the previously described KVLQT1 mutation, P448R.

\section{Materials and methods}

\subsection{LQTS subjects}

The proband from Family \#1 was diagnosed with LQTS in 1985 after several syncopal events while crossing the street or when sitting. Twelve-lead EKG showed a prolonged QT interval $\left(\mathrm{QT}_{\mathrm{C}}=500 \mathrm{~ms}\right)$. There was no family history of sudden death. She was treated with a dual-chamber pacemaker and beta-blocker therapy. She was found to have a KVLQT mutation [15], although her QT interval shortened with exercise and her 12-lead EKG showed low-amplitude, notched $\mathrm{T}$ waves more consistent of the LQT2 (HERG) subtype [16]. Her asymptomatic children were genotyped, and the 7-year-old son was found to carry the same LQT1 mutation. He was treated with beta-blocker medications and was offered a defibrillator implant. The family was of Chinese descent.

The proband from Family \#2 was diagnosed with LQTS in 2000 after syncopal events at age 27 and 33 while sitting. Her 12-lead EKG $\left(\mathrm{QT}_{\mathrm{C}}=520 \mathrm{~ms}\right.$; Fig. 1) also demonstrated the same low-amplitude, notched $\mathrm{T}$ waves as Patient \#1, and her QT interval also shortened with exercise. Her DNA was screened for LQTS mutations, and she was found to share the exact same base pair mutation in the KVLQT gene as Patient $\# 1$, although the two women were unrelated. She was also of Chinese descent.

\subsection{Control subjects}

Genomic DNA from 300 unrelated, healthy control subjects (100 African-American, 150 Caucasians/whites of European ancestry, and 50 Chinese) was obtained from volunteers without a personal or family history of LQTS or syncope. Ethnic background was by self-report that all four grandparents belonged to that ethnic group. Chinese volunteers also underwent 12-lead EKG recordings. The human study protocol was approved by the University of California, Davis Institutional Review Board. All patients gave informed consent for the study.

\subsection{Mutational analyses}

Mutation analyses were performed as previously described [17]. Protein-encoding exons of KVLQT1 and HERG were amplified from genomic DNA by polymerase chain reaction using the full-length genomic sequence and previously published intron- and exon-based primers [18]. The mutations were detected by denaturing high performance liquid chromatography using a Transgenomic WAVE (Omaha, Nebraska, NE) system, as previously described $[17,19]$. The precise sequences of the mutations were determined by sequence analysis.

\subsection{Mutation nomenclature}

All mutations were denoted using known and accepted nomenclature [20]. The single-letter amino acid code was used to designate missense mutations using the A422T format, i.e. at amino acid 422, the WT amino acid, alanine (A), is replaced by a threonine $(\mathrm{T})$ on one of the alleles.

\subsection{Site-directed mutagenesis}

Point mutations were introduced into HERG (H562P and $\mathrm{A} 422 \mathrm{~T}$ ) and KVLQT1 (P448R) $\mathrm{K}^{+}$channels in the plasmid 


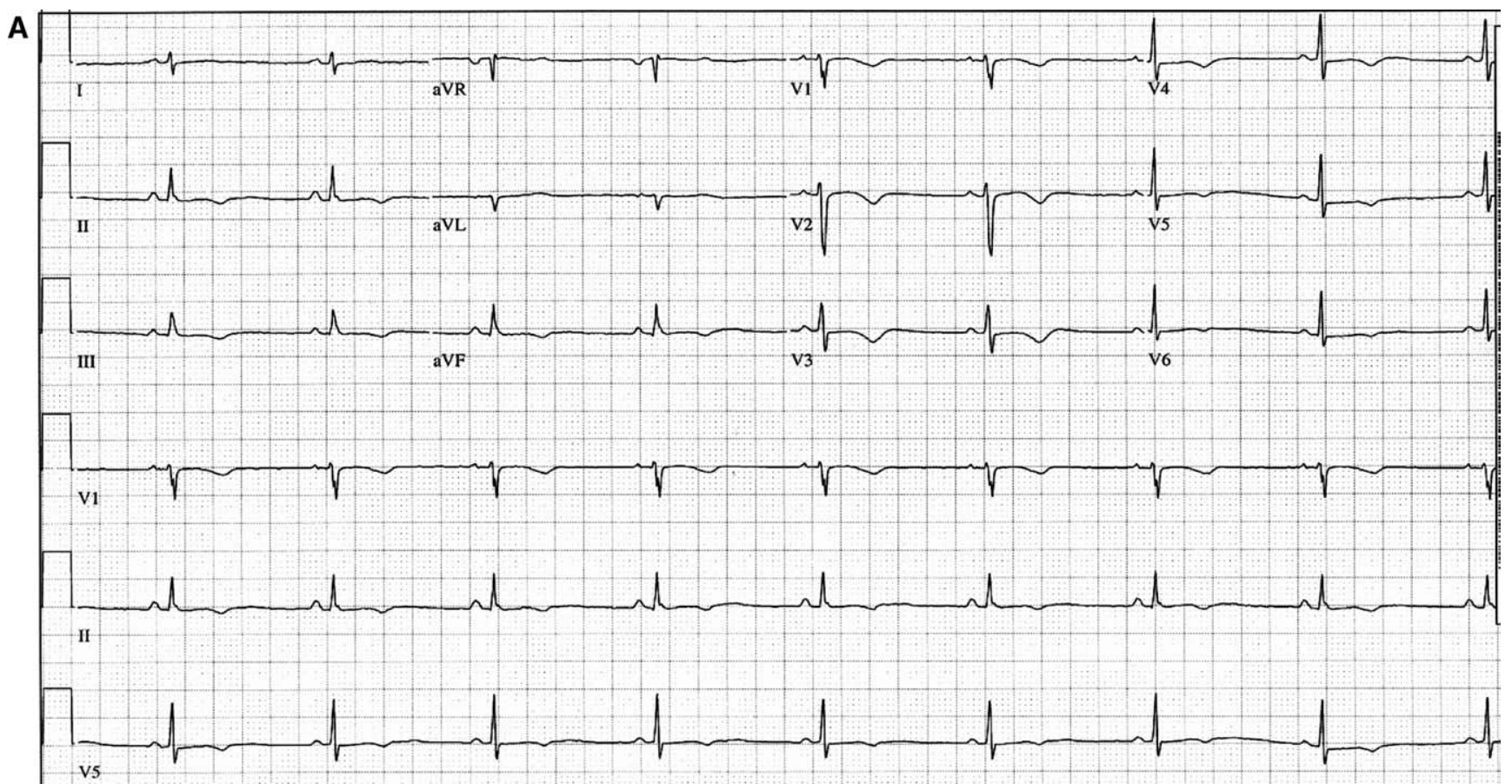

B

Proband

cheGTG CGACCCCCNAGAGAGCGG

P448R

C

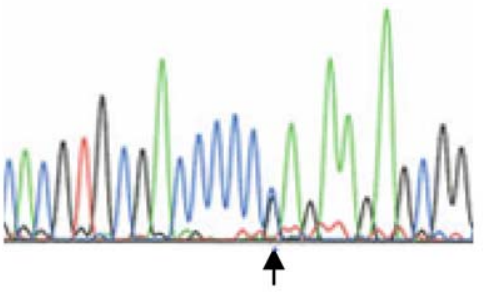

C1343

Proband

C T CA T C G C C C T G G C T G G C CT G

H562P

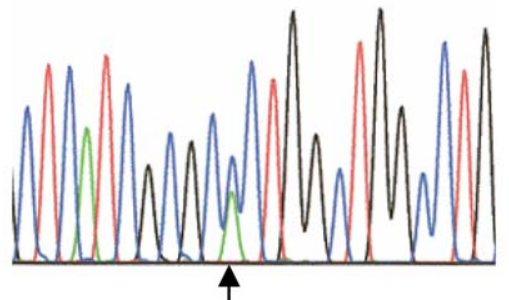

Control
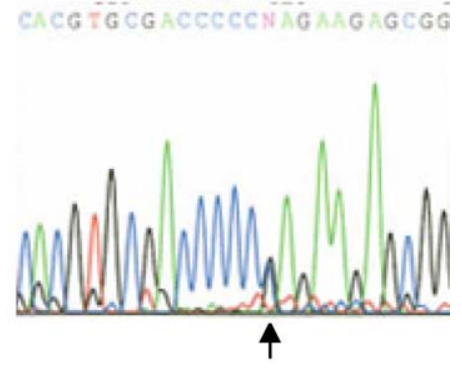

Control

C TCATCGCGCACT G GCTNGCCTG

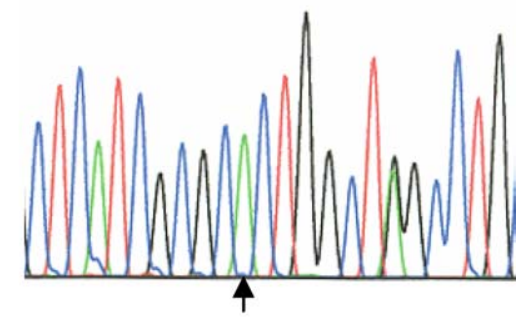

A1685

Fig. 1. (A) Twelve-lead EKG obtained from Patient \#2 showing evidence of QT prolongation $\left(\mathrm{QT}_{\mathrm{c}}=520 \mathrm{~ms}\right)$ as well as low-amplitude, notched T waves. (B) DNA sequence analysis of amplified exon 10 of $K V L Q T 1$ of one of the probands compared to one of the seven of the 50 normal controls ( $14 \%$ ) which reveals a C-to-G substitution at position 1343 and causes the P448R substitution (the purported LQT1 mutation). Both Patients \#1 and \#2 were further screened for possible mutations in HERG gene and were found to have unique, LQT2 mutations. (C,D) DNA sequence analysis of amplified exons 7 and 6 of $H E R G$ of the two probands compared to the reference alleles, which reveal an A-to-C substitution at position 1685 and causes the H562P substitution (in Patient \#1) and a G-to-A substitution at position 1264 and causes the A422T substitution (in Patient \#2), respectively. The two HERG missense mutations (A422T and H562P) are localized to S1 and S5 transmembrane segments of the HERG channel, respectively. (E) Pedigree of family of Patient \#1. Squares indicate males and circles, females. Affected individuals are represented by solid symbols while unaffected individuals are empty symbols.+ve and -ve represent positive and negative, respectively. 
D

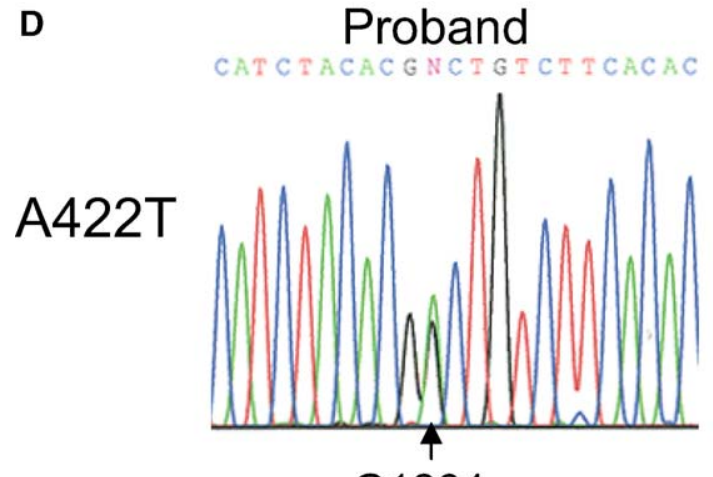

Control

CAT CTACACG G T TCI TCACAC

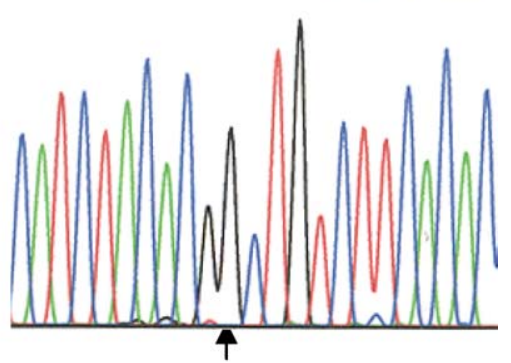

G1264

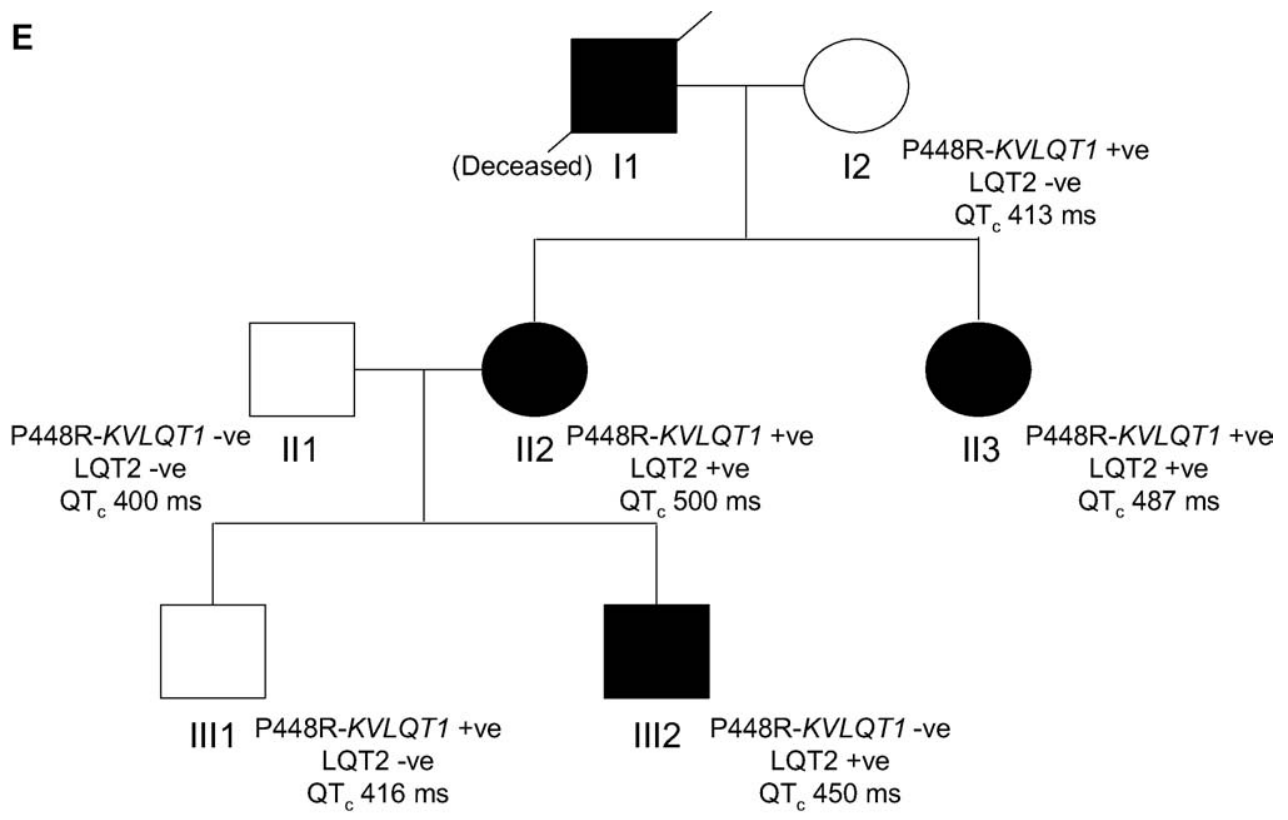

Fig. 1. (continued)

vector using QuickChange ${ }^{\mathrm{TM}}$ Site-Directed Mutagenesis kit (Stratagene, La Jolla, CA). Constructs were confirmed with restriction mapping and DNA sequencing.

\subsection{Transient transfection of HERG and KVLQT1 $K^{+}$ channels}

HEK 293 cells were maintained in Dulbecco's modified Eagle's medium containing 10\% fetal bovine serum, $2 \mathrm{mM}$ L-glutamine, and $1 \%$ penicillin and streptomycin. Cell cultures were kept at $37{ }^{\circ} \mathrm{C}$ in a $5 \% \mathrm{CO}_{2}$ incubator. Cells were transiently transfected with $H E R G$ cDNA, green fluorescent protein (GFP), and $h M i R P 1$ cDNA ( $h K C N E 2$ ) (kindly provided by Dr. Tomaselli, Johns Hopkins University, Baltimore, MD) using the calcium phosphate precipitation method (Invitrogen, Carlsbad, CA). GFP-positive cells were identified using the epifluorescence system and studied within 24-48 h of transfection.

Chinese Hamster ovarian (CHO) cells were maintained at $37{ }^{\circ} \mathrm{C}$ in HAM's F-12 medium containing $10 \%$ fetal bovine serum supplemented with $1 \%$ penicillin, streptomycin, and amphotericin. Cells were transiently transfected with $K V$ -
LQT1, KCNE1, (kindly provided by Pr. H. Bradley Nuss, University of Maryland, Baltimore, MD), and GFP cDNA using the lipofectamine method (Invitrogen). Electrophysiologic recordings were performed 24-48 $\mathrm{h}$ after transfection. CHO cells were used for KVLQT1 channel expression because these cells tend to express higher KVLQT1 current density. No direct comparison was made for current expressed in the two different cell types.

Mutant and the corresponding WT channels cDNA were transfected in parallel experiments using the same sets of cells. The amount of cDNA used for mutant and WT channels was kept constant throughout all experiments. Current recordings were then performed at the same time point in culture.

\subsection{Electrophysiologic recordings}

Membrane currents were measured using whole-cell patch-clamp techniques [21]. Cells were bathed in solution containing (in mmol/l) $\mathrm{NaCl} 140, \mathrm{KCl} 5.4, \mathrm{MgCl}_{2} 1, \mathrm{~N}-2$ hydroxyethylpiperazine- $N$-2-ethanesulphonic acid (HEPES) 10, glucose 10, and $\mathrm{CaCl}_{2}$ 2, $\mathrm{pH} 7.4$ (adjusted with $\mathrm{NaOH}$ ). 
The pipette solution contained (in mmol/l) $\mathrm{KCl} 140, \mathrm{MgCl}_{2}$ 1, HEPES 10, EGTA 5, and MgATP 4, pH 7.3 (adjusted with $\mathrm{KOH})$. Uncompensated capacitance currents in response to small hyperpolarizing voltage steps were recorded for offline integration as a means of measuring cell capacitance. All experiments were performed at room temperature (22$23{ }^{\circ} \mathrm{C}$ ) using an Axopatch 200A patch-clamp amplifier (Axon Instruments, Foster City, CA). Voltage commands and data collection were controlled using custom-written software. For whole-cell current recordings, the cell capacitance and series resistance were compensated. In general, 60-80\% of the series resistance was compensated. Current records were filtered at $2 \mathrm{kHz}$ and sampled at $10 \mathrm{kHz}$ using a fourpole Bessel filter.

Voltage protocols used in this study for evaluating $H E R G$ and its mutation are as follows (see also inset in the Figures): (1) voltage-dependent activation: prepulse for $4 \mathrm{~s}$ from -80 to $80 \mathrm{mV}$ in $10 \mathrm{mV}$ steps, test pulse to $-50 \mathrm{mV}$ for $6 \mathrm{~s}$. (2) Activation kinetics: incremental prepulse duration from 0.035 to $0.49 \mathrm{~s}$ at $0-60 \mathrm{mV}$ in $20 \mathrm{mV}$ steps, test pulse for $0.2 \mathrm{~s}$ at $-120 \mathrm{mV}$. (3) Steady-state inactivation and recovery from inactivation: prepulse to -140 from holding potential of $20 \mathrm{mV}$, depolarization to $50 \mathrm{mV}$ in $10 \mathrm{mV}$ steps for $0.03 \mathrm{~s}$ and a test pulse to $20 \mathrm{mV}$ for $0.17 \mathrm{~s}$. (4) Instantaneous currentvoltage relation and deactivation kinetics: prepulse to $-80 \mathrm{mV}$ from holding potential of $20 \mathrm{mV}$ for $0.03 \mathrm{~s}$, test pulse to -140 , depolarization to $40 \mathrm{mV}$ in $10 \mathrm{mV}$ steps for $1.6 \mathrm{~s}$. Voltage protocol used for determining KVLQT1 and P448R mutant channel for voltage-dependent activation: prepulse for $5 \mathrm{~s}$ from -80 to $90 \mathrm{mV}$ in $10 \mathrm{mV}$ steps, test pulse to $-50 \mathrm{mV}$ for $5 \mathrm{~s}$. Pooled data are presented as mean \pm SEM. Statistical comparison was performed using the Student's $t$-test and analysis of variance (where appropriate) with $P<0.05$ considered significant.

\section{Results}

Patient \#1 was diagnosed with LQTS after several syncopal events at age 27. She was treated with a dual-chamber pacemaker and beta-blocking agents. She was genotyped as LQT1 [11] although her QT interval shortened with exercise and showed low-amplitude, notched $\mathrm{T}$ waves more characteristic of LQT2 [16]. Her 7-year-old son was found to have the same LQT1 mutation and was started on beta-blocker therapy and was offered a defibrillator. She was of Chinese descent.

Patient \#2 was diagnosed with LQTS after syncopal events at age 27 and 33 while sitting; the latter occurred on beta-blocker therapy. She was found to have the same LQT1 mutation as Patient \#1 although they are not related. She also demonstrated low-amplitude, notched $\mathrm{T}$ waves on $\mathrm{EKG}$, again more typical of LQT2. Patient \#2 was also of Chinese descent. Fig. 1A shows the 12-lead EKG obtained from Patient \#2 showing evidence of QT prolongation.

In view of the discrepancy between the genotypic and phenotypic data on the two patients as well as the fact that the two probands were genetically unrelated but were both of Chinese descent, we questioned whether the previously found LQT1 mutation in the two patients represented a polymorphism rather than a disease-causing mutation. We decided to screen 50 healthy volunteers of Chinese descent who were not related to either patient and had no family or personal history suggestive of LQTS. Seven of the 50 controls (14\%) carried the same purported LQT1 mutation (Fig. 1B) and had an average $\mathrm{QT}_{\mathrm{C}}$ interval on EKG of $406 \mathrm{~ms}$. In contrast, none of the 150 Caucasian or 100 African-American controls carried the identified LQT1 variant.

Both patients were further screened for possible $H E R G$ mutations and were found to have unique $H E R G$ variants (A422T and H562P, Fig. 1C,D). The two HERG variants were absent in not only the 500 ethnically unmatched reference alleles but also absent in the 100 alleles derived from 50 ethnically similar Chinese volunteer. The two HERG variants were localized to the S1 and S5 transmembrane segments of the HERG channel, respectively. Patient \#1's 7-year-old son (who was being treated for LQTS) does not carry the newly identified $H E R G$ variant but her 5-year-old son (who was not being treated for LQTS) is positive for the $H E R G$ variant. Fig. 1E shows the pedigree of family of Patient \#1. Affected individuals are represented by solid symbols while unaffected individuals are represented by empty symbols. Patient \#2's infant daughter is LQT1 positive and LQT2 positive and is taking beta-blocker therapy.

To document directly that the previously reported P448R mutation in KVLQT1 most likely represents a genetic polymorphism present in the Chinese population, we performed functional analysis of the P448R mutant channel using heterologous expression system in $\mathrm{CHO}$ cells. Fig. 2A shows the representative $I_{\mathrm{Ks}}$ comparing WT KVLQT1/KCNE1 and $\mathrm{P} 448 \mathrm{R} / K C N E 1$ from a holding potential of $-80 \mathrm{mV}$. The summary data for the current density-voltage relations are shown in Fig. 2B. The voltage dependence of current activation was determined by fitting the relationship between tail currents at various test potentials with the Boltzmann function (Fig. 2C). The activation curve for KVLQT1/KCNE1 current shows a half-activation voltage $\left(V_{1 / 2}\right)$ of $50.14 \pm 3.82 \mathrm{mV}$ and a slope factor of $20.84 \pm 2.54 ; n=10$. The values obtained from $\mathrm{P} 448 \mathrm{R} / K C N E 1$ current are similar (a $V_{1 / 2}$ of $53.32 \pm 4.52 \mathrm{mV}$ and a slope factor of $21.63 \pm 2.79$; $n=12$ ).

To assess further whether the identified HERG mutations lead to alteration in channel function, we examined the function of the mutant channels compared to WT HERG channel in HEK 293 cells. Fig. 3A shows examples of $I_{\mathrm{Kr}}$ from WT $H E R G \mathrm{~K}^{+}$channel co-expressed with KCNE2 subunit elicited using depolarization steps from a holding potential of $-80 \mathrm{mV}$. Panels B and C shows currents recorded from the two identified HERG missense mutations co-expressed with $K C N E 2$ subunit. Both missense mutations resulted in a significant decrease in current density (note the difference in scale bar from WT current traces in Panel A). To test whether 
A
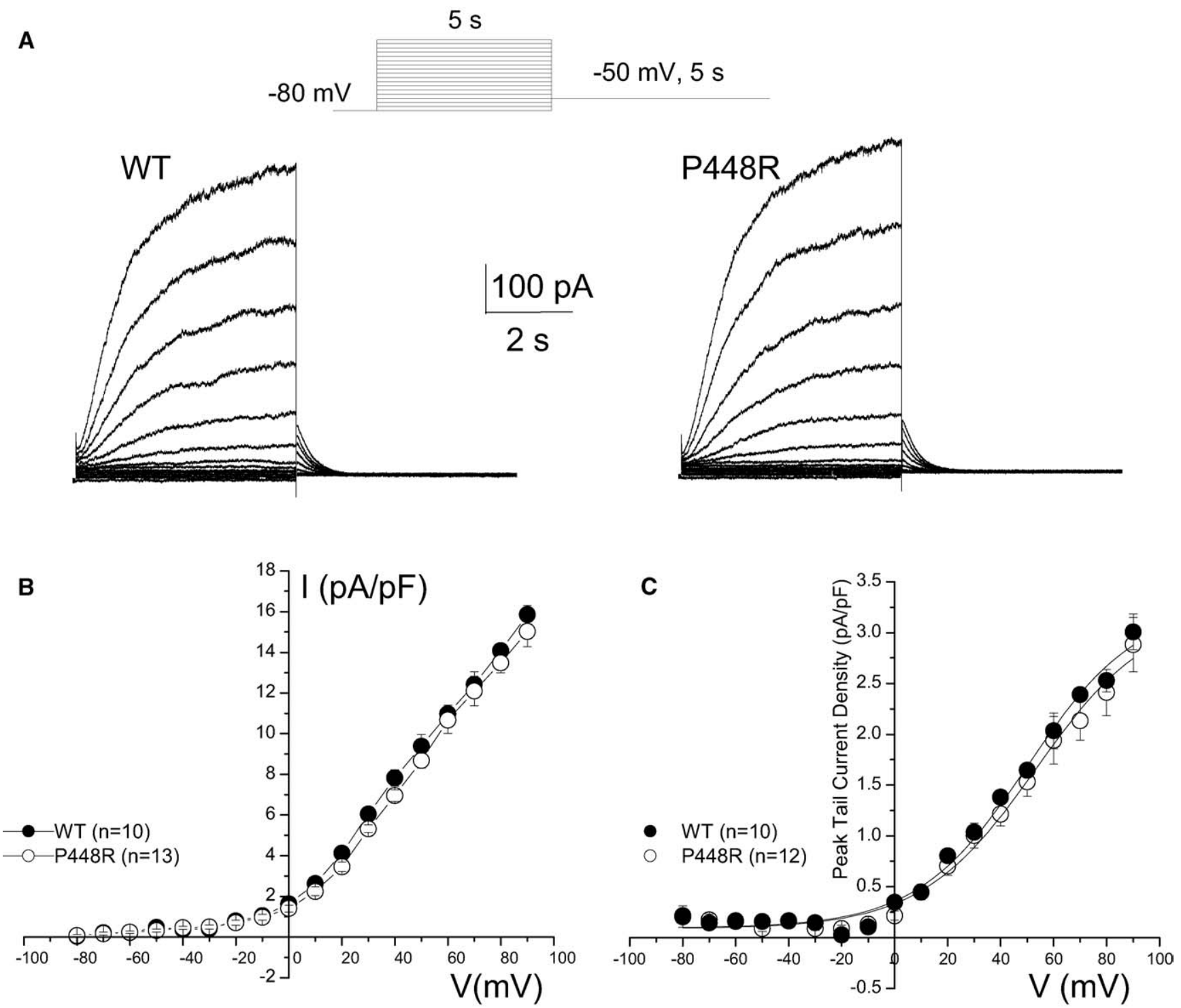

Fig. 2. Transient expression of the P448R-KVLQT1 mutant channel compared to WT channel in CHO cells. (A) Representative $I_{\mathrm{Ks}}$ current traces comparing WT KVLQT1/KCNE1 and P448R/KCNE1 from a holding potential of $-80 \mathrm{mV}$. (B) Summary data showing the current density-voltage relations obtained from P448R-KVLQT1 compared to WT channels. (C) The voltage dependence of current activation was determined by fitting the relationship between tail currents at various test potentials with the Boltzmann function. The activation curve for $K V L Q T 1 / K C N E 1$ current shows a half-activation voltage ( $V_{1 / 2}$ ) of $50.14 \pm 3.82 \mathrm{mV}$ and a slope factor of $20.84 \pm 2.54 ; n=10$. The values obtained from P448R/KCNE1 current are similar (a $V_{1 / 2}$ of $53.32 \pm 4.52 \mathrm{mV}$ and a slope factor of $21.63 \pm 2.79 ; n=12$ ).

these mutations could result in the dominant-negative suppression of the WT $I_{\mathrm{Kr}}$ current, we co-expressed the mutant channel together with WT HERG and KCNE2 subunits in the ratio of $1: 1: 1$. Panels $\mathrm{D}$ and $\mathrm{E}$ show a significant dominantnegative suppression on the WT HERG $\mathrm{K}^{+}$current from co-expression with either of the missense mutations. Summary data are shown in Panels F and G illustrating a significant decrease in the WT current density at all test potentials from co-expression with the mutant channels. The WT HERG $\mathrm{K}^{+}$current shows a rectification with maximum outward current at a test potential of $+10 \mathrm{mV}$, in contrast, the rectification was lost with co-expression with the mutant channels. These findings suggest that the two identified missense mutations in HERG $\mathrm{K}^{+}$channel are likely the diseasecausing mutations in the two LQTS families.
Tail current amplitude, normalized to cell capacitance, was used to construct the activation curves shown in Fig. 4A. The amplitude of the peak tail current for H562P/ HERG/KCNE2 and A422T/HERG/KCNE2 was significantly smaller $(P<0.0001)$ than that of WT HERG/KCNE2. The threshold activation voltage for WT HERG/KCNE2 current was close to $-50 \mathrm{mV}$ and the current was fully activated at voltage steps more positive to $+10 \mathrm{mV}$. When fit with Boltzmann functions, the half-maximum activation voltage $\left(V_{1 / 2}\right)$ and slope factor $(k)$ for WT HERG/KCNE2 was $-20.12 \pm 0.31 \mathrm{mV}$ and $8.24 \pm 0.27$, respectively. The values for A422T/HERG/KCNE2 and H562P/HERG/KCNE2 were $-29.49 \pm 1.28 \mathrm{mV}\left(V_{1 / 2}\right)$ and $6.50 \pm 1.101(k)$ and $-39.77 \pm 2.20 \mathrm{mV}\left(V_{1 / 2}\right)$ and $5.04 \pm 1.96(k)$, respectively (Fig. 4A). 


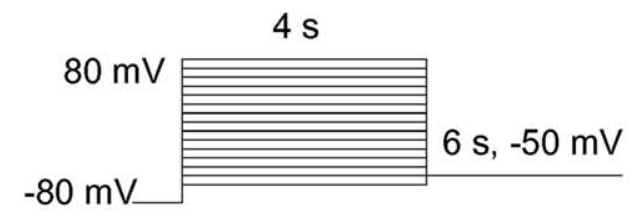

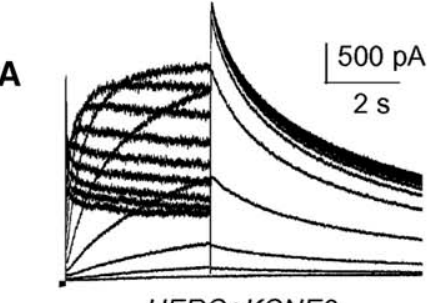

HERG+KCNE2
B

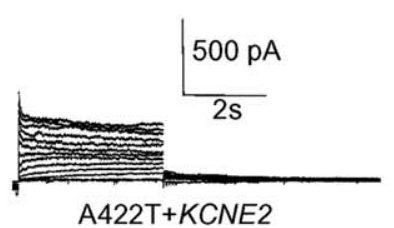

C

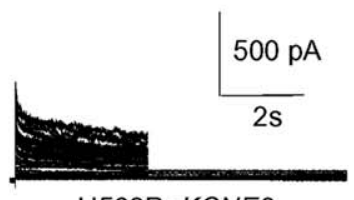

$\mathrm{H} 562 \mathrm{P}+K C N E 2$

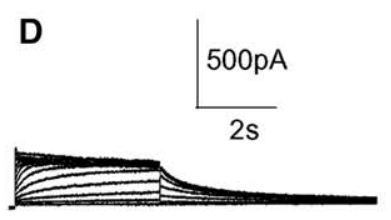

$\mathrm{A} 422 \mathrm{~T}+H E R G+K C N E 2$

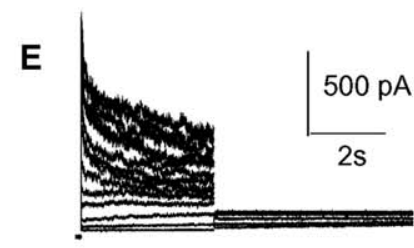

$\mathrm{H} 562 \mathrm{P}+H E R G+K C N E 2$

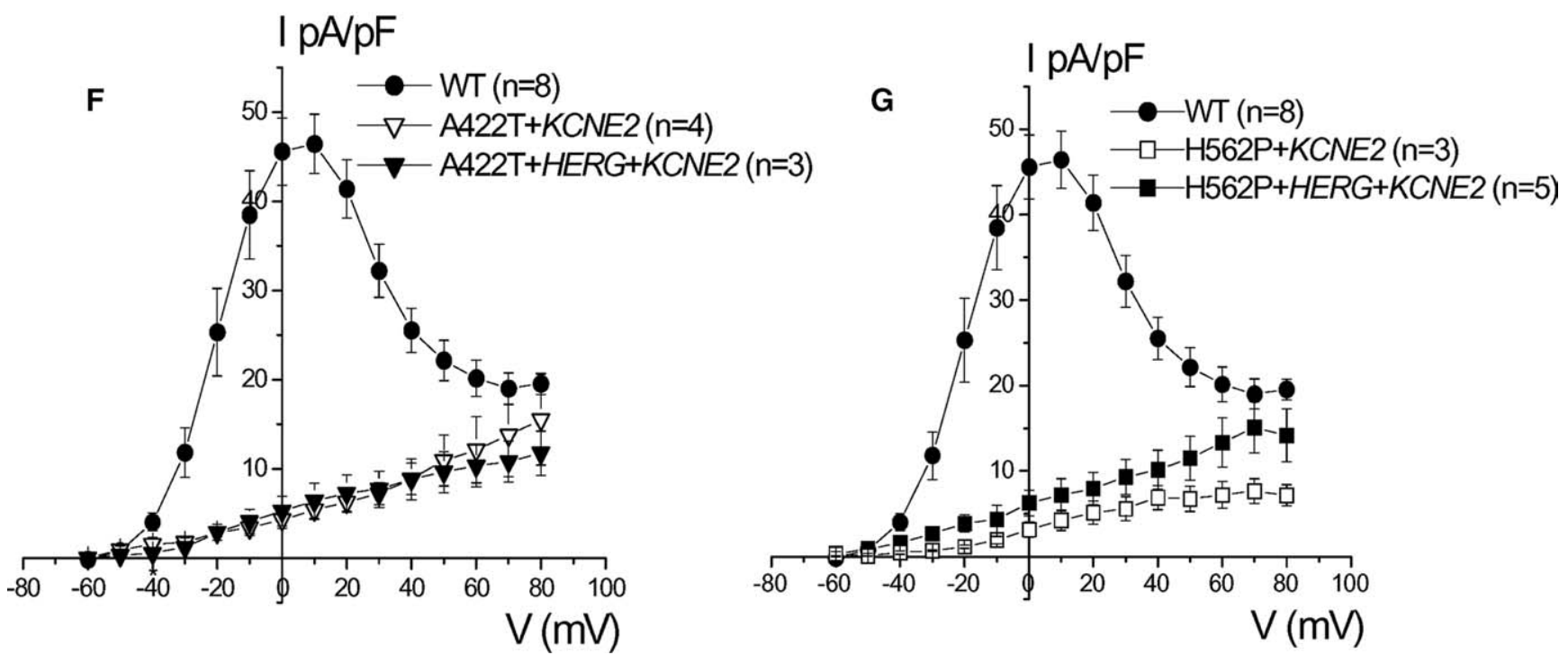

Fig. 3. Transient expression of A422T- and H562P-HERG mutant channel in HEK 293 cells. (A) Representative current traces of $I_{\mathrm{Kr}}$ from WT $H E R G \mathrm{~K}^{+}$channel co-expressed with $K C N E 2$ subunit elicited using depolarization steps from a holding potential of $-80 \mathrm{mV}$. (B,C) Representative currents recorded from A422T and H562P missense mutant channels co-expressed with KCNE2 subunit. Both missense mutations resulted in a significant decrease in current density (note the difference in scale bar from WT current traces in Panel A). (D,E) Dominant-negative suppression of the WT $I_{\mathrm{Kr}}$ current when WT HERG channel was co-expressed with one of the mutant channels and KCNE2 subunit in the ratio of 1:1:1. Summary data are shown in Panels F and G illustrating a significant decrease in the WT current density at all test potentials from co-expression with the mutant channels.

At all test potentials examined $(0,20,40$, and $60 \mathrm{mV})$, the activation time constants for H562P or A422T mutant channels were not significantly different from those of WT channel (Fig. 4B). The time course for deactivation was examined by fitting the decay of tail current with the double exponential function yielding the fast $\left(\tau_{\text {fast }}\right)$ and slow $\left(\tau_{\text {slow }}\right)$ time constants (Fig. 4C). There were no significant differences in the fast or slow deactivation time constants in mutants A422T $(n=3)$ as compared to WT channel $(n=7)$. However, the H562P mutant channel showed a significant decrease in slow deactivation time constants at test potentials of -120 and $-130 \mathrm{mV}$ as compared to WT channel, whereas $\tau_{\text {fast }}$ remained similar. The instantaneous current density and voltage (Fig. 4D) showed a significant decrease in the current amplitude in $\mathrm{H} 562 \mathrm{P} / H E R G / K C N E 2(n=3)$ and mutation A422T/HERG/KCNE2 $(n=3)$ as compared with WT 


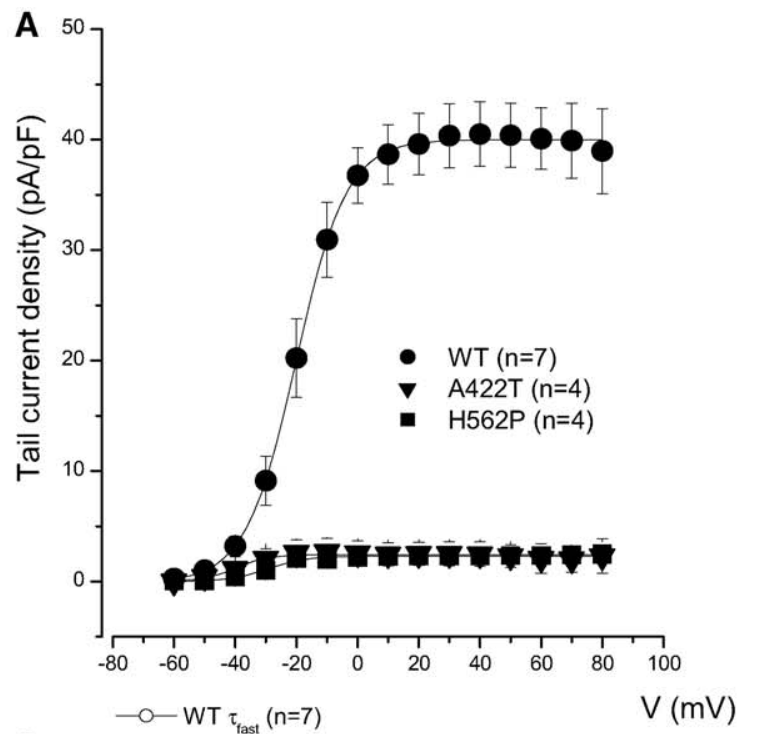

C $\quad \longrightarrow W T \tau_{\text {slow }}(n=7)$
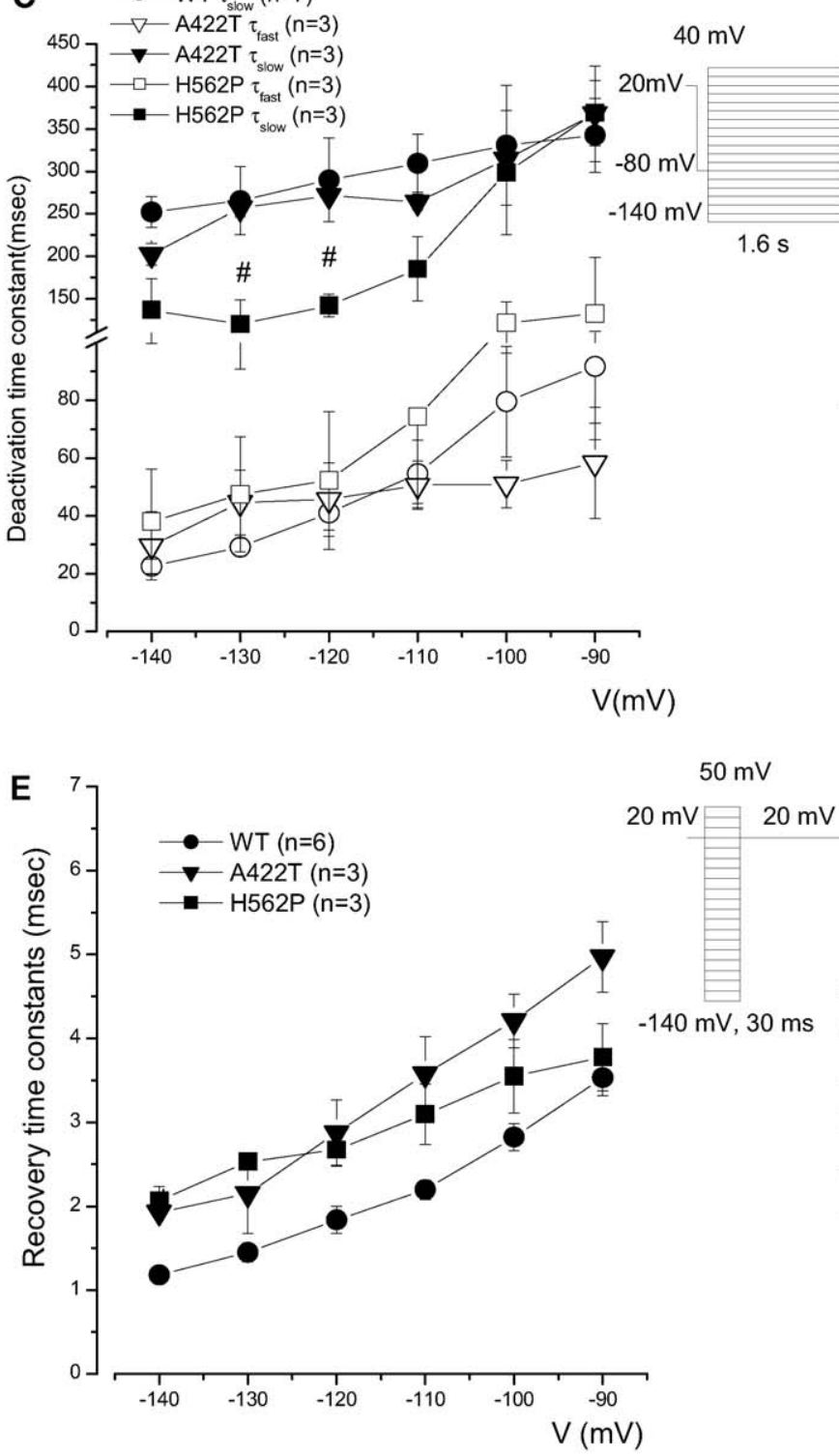

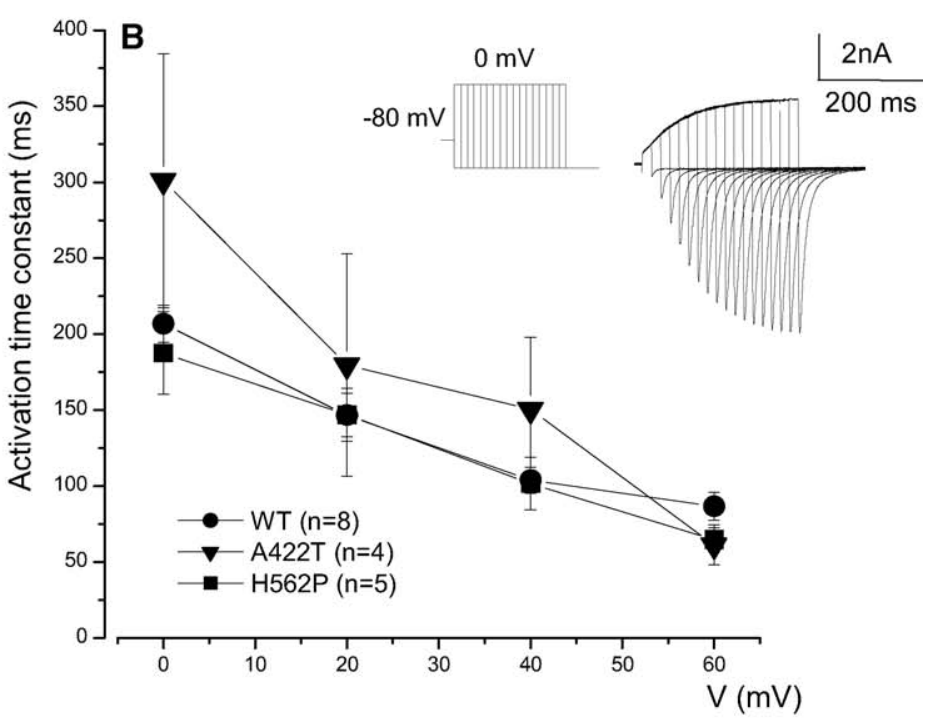

D
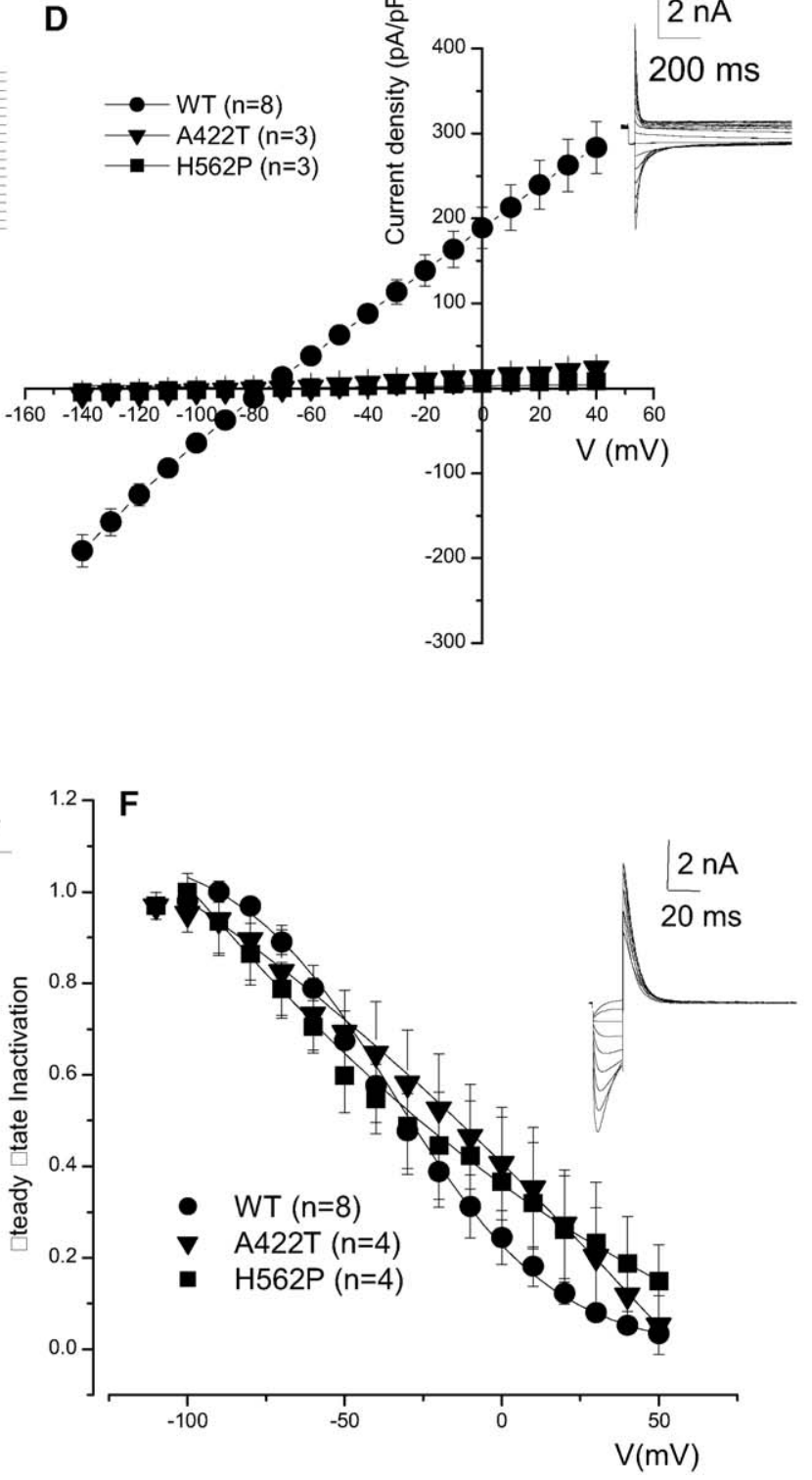
HERG/KCNE2 $(n=8)$. The estimated reversal potential for WT HERG/KCNE2 was close to $-76 \mathrm{mV}$, similar to those of H562P/HERG/KCNE2 and A422T/HERG/KCNE2 (-72 and $-70 \mathrm{mV}$, respectively). The time constant of recovery from inactivation was measured as a mono exponential fit to the rising phase of the tail current. At all test potentials, the kinetics of recovery from inactivation in H562P $(n=3)$ and A422T mutant channels $(n=3)$ were not significantly different from WT channels ( $n=6$; Fig. 4E). Similarly, there were no significant differences in the steady-state inactivation between WT and the two mutant channels (Fig. 4F).

\section{Discussion}

The $K V L Q T 1$ variant $\mathrm{C} 1343 \mathrm{G}$, leading to an amino acid substitution, $\mathrm{P} 448 \mathrm{R}$ in $\mathrm{C}$ terminus was previously reported as an LQT1-causing mutation [15]. In this study, we demonstrate the presence of P448R in two genetically unrelated Chinese LQTS families. Although absent among 500 reference alleles derived from 150 white and 100 African-American subjects, P448R was also present in $14 \%$ of normal, healthy volunteers of Chinese descent, which suggests that the mutation may represent an ethnic-specific, common polymorphism rather than an LQT1-causing mutation. To further ascertain that the P448R-KVLQT1 does indeed represent a polymorphism, we carried out functional studies using the heterologous expression system. Expression of P448RKVLQT1 yielded normal, WT currents with kinetics that were indistinguishable from the WT currents. In contrast, the two unique HERG mutations resulted in significant dominant-negative suppression of the WT HERG channel and are most likely the disease-causing mutations in the two families. Our study underscores the importance of distinguishing channel polymorphisms from disease-causing mutations pathogenic for LQTS and emphasizes the importance of using appropriate ethnically matched controls in the genotypic analysis of LQTS. Indeed, one child of the original proband was initially diagnosed with LQT1 based upon the presence of the $\mathrm{P} 448 \mathrm{R}-K V L Q T 1$ variant and was treated with beta-blockers. However, he did not possess the subsequently determined LQT2-causing mutation. On the other hand, his untreated P448R-negative brother harbored the true, diseasecausing HERG mutation and was not being treated for LQTS.

\section{1. $K^{+}$channel variants}

Our data agrees well with previous studies, which suggested that the KVLQT1 variant $\mathrm{P} 448 \mathrm{R}$ may represent a common polymorphism in Asian subjects since the variant was identified in 22-28\% of Japanese subjects [22] and $16.4 \%$ of the Asian subjects [19]. However, none of these prior studies have carried out functional analyses of the purported channel variants. Importantly, our study using functional expression further confirms that P448R-KVLQT1 most likely represents a benign polymorphism with no detectable changes in the current kinetics or expression level compared to the WT channel, and further that the identified polymorphism was ethnic specific.

Polymorphisms in the human genome are common and may be implicated in physiological variability or in drug response in a wide range of diseases [23,24]. Polymorphisms are well recognized in non-coding regions of DNA where they may contribute to regulation of gene function. Some DNA variants have previously been shown to predispose individuals to the drug-induced, acquired form of LQTS and have been reported in congenital LQT disease genes $[6,22,25,26]$. Indeed, DNA variants in the coding regions of congenital LQT disease genes have recently been identified in $\sim 10-15 \%$ of affected subjects, predominantly in genes encoding ancillary subunits [22]. Most of the individuals with polymorphisms will never have arrhythmias because of the subtle effect of these polymorphisms upon the channel function. However, if exposed to additional acquired risk factors such as medications, hypokalemia, or structural heart disease, such patients may be at increased risk for arrhythmias or sudden death [25-27]. For ion channel variants, it has previously been observed that most of the common polymorphisms are located in the amino- and carboxy-termini, and that these regions may be more tolerant of amino acid substitution than other regions of the channel [19]. For the identified P448R-KVLQT1 variant in our study, there was no history of drug-induced arrhythmias in any of our healthy Chinese control subjects. This most likely represents a benign polymorphism as suggested by our heterologous expression study.

Fig. 4. (A) Voltage dependent of activation was constructed from tail current density. The amplitude of the peak tail current for H562P/HERG/KCNE2 and A422T/HERG/KCNE2 were significantly smaller $(P<0.0001)$ than that of WT HERG/KCNE2. Solid lines represent fit to the Boltzmann functions, the half-maximum activation voltage $\left(V_{1 / 2}\right)$ and slope factor $(k)$ for WT HERG/KCNE2 was $-20.12 \pm 0.31 \mathrm{mV}$ and $8.24 \pm 0.27$, respectively. The values for A422T/HERG/KCNE2 and H562P/HERG/KCNE2 were $-29.49 \pm 1.28 \mathrm{mV}\left(V_{1 / 2}\right)$ and $6.50 \pm 1.101(k)$ and $-39.77 \pm 2.20 \mathrm{mV}\left(V_{1 / 2}\right)$ and $5.04 \pm 1.96(k)$, respectively. (B) Activation time constants at test potentials of 0, 20, 40 and $60 \mathrm{mV}$ for H562P or A422T mutant channels were not significantly different from those of the WT channel. The pulse protocol used is shown in the inset together with representative traces obtained from the WT channel at a test potential of $0 \mathrm{mV}$. (C) There were no significant differences in the fast or slow deactivation time constants in mutants A422T $(n=3)$ as compared to the WT channel $(n=7)$. However, the H562P mutant channel showed a significant decrease in the slow deactivation time constants at test potentials of -120 and $-130 \mathrm{mV}$ as compared to the WT channel, whereas $\tau_{\text {fast }}$ remained similar. The pulse protocol used is shown in the inset. (D) The instantaneous current density-voltage relations showing a significant decrease in the current amplitude in H562P/HERG/KCNE2 $(n=3)$ and mutation A422T/HERG/KCNE2 $(n=3)$ as compared with WT HERG/KCNE2 $(n=8)$. The instantaneous current density-voltage relations were obtained using the same protocol as shown in C. (E) Time constant of recovery from inactivation was measured as a mono exponential fit to the tail current rising phase. The pulse protocol used is shown in the inset. (F) The steady-state inactivation obtained using the same protocol as in E from WT and the two mutant channels are shown. Representative traces from the WT channel is shown in the inset. 


\subsection{Specific phenotypes in $L Q T$ patients}

Specific phenotypes have been associated with the three main genetic subtypes of LQT1, LQT2, and LQT3 [27,28]. LQT1 appears to be the most adrenaline-sensitive of the subtypes in that episodes frequently occur during exercise, swimming, or with strong emotion, and beta-blocker medications work well at reducing episodes in this subtype [16]. LQT2 is classically associated with auditory stimuli, and these patients respond variably to beta-blockers [16,29]. LQT3 is relatively rare, representing only $5-10 \%$ of all LQTS patients [11]. Typically they have episodes while sleeping, and are believed to have the lowest event rate but highest mortality with events, and may respond well to pacemaker therapy alone [16,28,30].

The clinical phenotype in our two Chinese probands was more consistent with the LQT2 subtype including their presentation, EKG features, and results of exercise testing. Indeed, the inconsistencies between their published genotype (LQT1) and their phenotype (LQT2) led us to a renewed search to uncover their LQT2 mutations.

\subsection{Functional analysis}

Our results, as well as recent studies suggesting ethnic differences in cardiac $\mathrm{K}^{+}$channel variants further underscores the fact that extreme caution must be used in assigning a channel variant the status of a pathogenic channel mutation causing congenital LQTS. In general, the criteria used include identification of a non-synonymous variant including single nucleotide substitutions, deletions and insertions, absence of that variant in the controls as well as conservation of that particular amino acid through various species. If a particular channel variant has been identified in a small number of affected family members precluding genetic linkage analysis of multigenerational families, functional analysis will need to be performed to determine whether the identified variant results in a functionally abnormal channel.

The "gold standard" of determining which mutations are benign vs. disease causing is through functional analysis of the mutations, as we did through patch-clamp analysis. We demonstrated for the first time in the present study that the purported P448R polymorphism does not affect the $I_{\mathrm{Ks}}$ current. We have shown that the novel H562P and A4225 mutations in the HERG channel in our probands resulted in marked reduction of the $\mathrm{K}^{+}$current, specifically the expected dominant-negative suppression of the HERG current.

We conclude that the two novel HERG mutations in these families indeed affect the $\mathrm{K}^{+}$channel function and are causative agents for their LQTS. We do not know what, if any, clinical effects the $\mathrm{P} 448 \mathrm{R}$ polymorphism has. It was found in $14 \%$ of our healthy Chinese volunteers who had normal EKG findings and no symptoms suggestive of LQTS.

\subsection{Clinical implications}

Our study has implications for genetically based research. In our first LQTS family, the two children of the proband were given incorrect diagnoses regarding their LQTS status. One child with the Asian DNA polymorphism was being treated for a disease he did not have, whereas his affected brother carried the disease-causing mutation but did not receive treatment. This study highlights the need to include members of different ethnic groups as control subjects when performing genomic DNA studies. Such inclusion should limit mislabeling ethnically based benign DNA polymorphisms as disease-causing mutations.

\section{Acknowledgements}

Supported by NIH (RO1 HL68507 and HL67737) to N.C. and by the AHA (Western States Affiliates Beginning-Grantin-Aid) and Pfizer/SWHR Scholar Grant to K.A.G. The authors thank Dr. E.N. Yamoah (Center for Neuroscience, University of California, Davis) for critical comments on the manuscript.

\section{References}

[1] Wang Q, Shen J, Li Z, Timothy K, Vincent GM, Priori SG, et al. Cardiac sodium channel mutations in patients with long QT syndrome, an inherited cardiac arrhythmia. Hum Mol Genet 1995;4: 1603-7.

[2] Wang Q, Shen J, Splawski I, Atkinson D, Li Z, Robinson JL, et al. SCN5A mutations associated with an inherited cardiac arrhythmia, long QT syndrome. Cell 1995;80:805-11.

[3] Wang Q, Curran ME, Splawski I, Burn TC, Millholland JM, VanRaay TJ, et al. Positional cloning of a novel potassium channel gene: KVLQT1 mutations cause cardiac arrhythmias. Nat Genet 1996;12: $17-23$.

[4] Curran ME, Splawski I, Timothy KW, Vincent GM, Green ED, Keating MT. A molecular basis for cardiac arrhythmia: HERG mutations cause long QT syndrome. Cell 1995;80:795-803.

[5] Splawski I, Tristani-Firouzi M, Lehmann MH, Sanguinetti MC, Keating MT. Mutations in the hminK gene cause long QT syndrome and suppress IKs function. Nat Genet 1997;17:338-40.

[6] Abbott GW, Sesti F, Splawski I, Buck ME, Lehmann MH, Timothy $\mathrm{KW}$, et al. MiRP1 forms $I \mathrm{Kr}$ potassium channels with HERG and is associated with cardiac arrhythmia. Cell 1999;97:175-87.

[7] Sanguinetti MC, Curran ME, Zou A, Shen J, Spector PS, Atkinson DL, et al. Coassembly of K(V)LQT1 and minK (IsK) proteins to form cardiac $I(\mathrm{Ks})$ potassium channel. Nature 1996;384:80-3.

[8] Sanguinetti MC, Curran ME, Spector PS, Keating MT. Spectrum of HERG $\mathrm{K}^{+}$-channel dysfunction in an inherited cardiac arrhythmia. Proc Natl Acad Sci USA 1996;93:2208-12.

[9] Sanguinetti MC, Jiang C, Curran ME, Keating MT. A mechanistic link between an inherited and an acquired cardiac arrhythmia: HERG encodes the $I \mathrm{Kr}$ potassium channel. Cell 1995;81:299-307.

[10] Plaster NM, Tawil R, Tristani-Firouzi M, Canun S, Bendahhou S, Tsunoda A, et al. Mutations in Kir 2.1 cause the developmental and episodic electrical phenotypes of Andersen's syndrome. Cell 2001; 105:511-9.

[11] Keating MT, Sanguinetti MC. Molecular and cellular mechanisms of cardiac arrhythmias. Cell 2001;104:569-80.

[12] Mohler PJ, Schott JJ, Gramolini AO, Dilly KW, Guatimosim S, duBell WH, et al. Ankyrin-B mutation causes type 4 long-QT cardiac arrhythmia and sudden cardiac death. Nature 2003;421:634-9.

[13] Barhanin J, Lesage F, Guillemare E, Fink M, Lazdunski M, Romey G. $\mathrm{K}_{\mathrm{V}} \mathrm{LQT} 1$ and IsK (minK) proteins associate to form the $I_{\mathrm{Ks}}$ cardiac potassium current. Nature 1996;384:78-80. 
[14] Armstrong CM, Hille B. Voltage-gated ion channels and electrical excitability. Neuron 1998;20:371-80.

[15] Splawski I, Shen J, Timothy KW, Lehmann MH, Priori S, Robinson JL, et al. Spectrum of mutations in long-QT syndrome genes. KVLQT1, HERG, SCN5A, KCNE1, and KCNE2. Circulation 2000; 102:1178-85.

[16] Schwartz PJ, Priori SG, Spazzolini C, Moss AJ, Vincent GM, Napolitano C, et al. Genotype-phenotype correlation in the long-QT syndrome: gene-specific triggers for life-threatening arrhythmias. Circulation 2001;103:89-95.

[17] Ackerman MJ, Siu BL, Sturner WQ, Tester DJ, Valdivia CR, Makielski JC, et al. Postmortem molecular analysis of SCN5A defects in sudden infant death syndrome. JAMA 2001;286:2264-9.

[18] Splawski I, Shen J, Timothy KW, Vincent GM, Lehmann MH, Keating MT. Genomic structure of three long QT syndrome genes: KVLQT1, HERG, and KCNE1. Genomics 1998;51:86-97.

[19] Ackerman MJ, Tester DJ, Jones GS, Will ML, Burrow CR, Curran ME. Ethnic differences in cardiac potassium channel variants: implications for genetic susceptibility to sudden cardiac death and genetic testing for congenital long QT syndrome. Mayo Clin Proc 2003;78:1479-87.

[20] Antonarakis SE. Recommendations for a nomenclature system for human gene mutations. Hum Mutat 1998;11:1-3 Nomenclature Working Group.

[21] Hamill OP, Marty A, Neher E, Sakmann B, Sigworth FJ. Improved patch-clamp techniques for high-resolution current recording from cells and cell-free membrane patches. Pflugers Arch 1981;391:85100.
[22] Yang P, Kanki H, Drolet B, Yang T, Wei J, Viswanathan PC, et al. Allelic variants in long-QT disease genes in patients with drugassociated torsades de pointes. Circulation 2002;105:1943-8.

[23] Collins FS, Brooks LD, Chakravarti A. A DNA polymorphism discovery resource for research on human genetic variation. Genome Res 1998;8:1229-31.

[24] Roses AD. Pharmacogenetics and the practice of medicine. Nature 2000:405:857-65.

[25] Sesti F, Abbott GW, Wei J, Murray KT, Saksena S, Schwartz PJ, et al. A common polymorphism associated with antibiotic-induced cardiac arrhythmia. Proc Natl Acad Sci USA 2000;97:10613-8.

[26] Napolitano C, Schwartz PJ, Brown AM, Ronchetti E, Bianchi L, Pinnavaia A, et al. Evidence for a cardiac ion channel mutation underlying drug-induced QT prolongation and life-threatening arrhythmias. J Cardiovasc Electrophysiol 2000;11:691-6.

[27] Vincent GM, Timothy KW, Leppert M, Keating M. The spectrum of symptoms and QT intervals in carriers of the gene for the long-QT syndrome. New Engl J Med 1992;327:846-52.

[28] Zareba W, Moss AJ, Schwartz PJ, Vincent GM, Robinson JL, Priori SG, et al. Influence of genotype on the clinical course of the long-QT syndrome. New Engl J Med 1998;339:960-5 International Long-QT Syndrome Registry Research Group.

[29] Wilde AA, Jongbloed RJ, Doevendans PA, Duren DR, Hauer RN, van Langen IM, et al. Auditory stimuli as a trigger for arrhythmic events differentiate HERG-related (LQTS2) patients from KVLQT1-related patients (LQTS1). J Am Coll Cardiol 1999;33:327-32.

[30] van den Berg MP, Wilde AA, Viersma TJW, Brouwer J, Haaksma J, van der Hout $\mathrm{AH}$, et al. Possible bradycardiac mode of death and successful pacemaker treatment in a large family with features of long QT syndrome type 3 and Brugada syndrome. J Cardiovasc Electrophysiol 2001;12:630-6. 